\title{
A SOCIEDADE CIVIL É BURGUESA?
}

\author{
Alfredo de Oliveira Moraes ${ }^{1}$
}

\section{Resumo:}

Hegel buscou em seus Princípios da Filosofia do Direito uma resolução para a antinomia moderna entre Estado e sociedade civil esboçada numa Filosofia da História particular, a qual desenvolvera uma irreconciliável oposição entre liberdade real e democracia. Tais Princípios logo chamarão a atenção do Marx republicano no momento em que este tensionava-se com a dialética hegeliana e os movimentos comunistas que insurgiam na França. Para Hegel, a razão mais filosófica teria ultrapassado o momento do Estado democrático porque este fora a razão em sua consciência infantil obrigando-a a realizar-se absolutamente consciente apenas na unidade madura de uma Monarquia Constitucional. Para Marx, entretanto, a irrevogabilidade da perdição da inocência de Hegel é antes a admissão de uma irrevogabilidade do domínio da propriedade privada, a qual fundamentara a ilusão de uma solução formal como solução real. A Crítica à Filosofia do Direito de Hegel de Marx indicará que apenas a dissolução do interesse público como uma forma em si traria a liberdade humana efetiva e que o aprofundamento da democracia demandaria justamente tal dissolução ao desenvolver a dissolução da propriedade privada em seu caráter de interesse público.

Palavras-chave: História, Direito, Razão, Estado, Propriedade privada.

\begin{abstract}
:
Hegel sought in his Principles of Philosophy of Right a resolution to the modern antinomy between State and civil society outlined in a particular Philosophy of History, which had developed an irreconcilable opposition between real freedom and democracy. These principles will catch soon the attention of the Republican Marx at the time he was tensioned with the Hegelian dialectic and communist movements that emerged in France. According to Hegel, the most philosophical reason would have exceeded the time of the democratic State, because this was the reason in its children's consciousness forcing it to make itself absolutely conscious only in the mature unit of a Constitutional Monarchy. For Marx, however, Hegel's irrevocability of innocence destruction is before the admission of an irrevocability of the private property domain, which has substantiated the illusion of a formal solution as a real solution. The work Critique of Hegel's Philosophy of Right written by Marx indicates that only the public interest dissolution, as a way in itself, would bring the effective human freedom and that the strengthening of democracy would demand exactly such dissolution to develop the dissolution of private property in its character of public interest.
\end{abstract}

Keywords: History, Law, Reason, State, Private property.

\footnotetext{
${ }^{1}$ Professor Adjunto do Departamento de Filosofia e do Programa de Pós-graduação da UFPE, Docente do Programa Interinstitucional de Doutorado em Filosofia UFRN/UFPB/UFPE. Doutor em Filosofia pela UFRGS. Autor entre outros de "A Metafísica do Conceito", EDIPUCRS.
} 
A burguesia desempenhou na história um papel altamente revolucionário. (...) A burguesia não pode existir senão a condição de revolucionar incessantemente os instrumentos de produção e, por conseguinte, as relações de produção, e com isso todas as relações sociais. (...) Mercê ao rápido aperfeiçoamento dos instrumentos de produção e ao constante progresso dos meios de comunicação, a burguesia arrasta para a corrente da civilização a todas as nações, até as mais bárbaras. Os baixos preços de suas mercadorias constituem a artilharia pesada que derruba todas as muralhas da China e (...) obriga a todas as nações, se não querem sucumbir, a adotar o modo burguês de produção, as constrange a introduzir a chamada civilização, isto é, a fazerem-se burguesas. Em uma palavra, forja um mundo a sua imagem e semelhança.

Karl Marx \& F. Engels (Manifesto do Partido Comunista, p.35-36)

No seu célebre texto "Princípios (Linhas Fundamentais) da Filosofia do Direito" (Grundlinien der Philosophie des Rechts oder Naturrecht und Staatswissenschaft im Grundrisse), G. W. F. Hegel ao revolucionar as teorias do Estado até então vigentes, introduz entre a Família e o Estado a Sociedade Civil, e a denomina - Burguesa, pois aí vê a sua determinação essencial. Que significa isto? Iremos nos ocupar brevemente dessa questão e tentar discorrer um pouco sobre a sua atualidade.

A condenação à Burguesia desde há algum tempo se tornou universal e se popularizou, sobretudo, porque se confunde e se reduz a burguesia, com todo o seu conjunto de princípios, com o sistema econômico que lhe dá suporte, ou mais precisamente, com as mazelas desse sistema econômico, muito raramente alguém lembra que se, por exemplo, Buda ou Jesus ou Maomé tivessem de ser julgados pelos desdobramentos dados pelos homens às idéias que eles nos legaram, a condenação que sofreriam com muita probabilidade seria muito mais severa.

Especialmente no Brasil, que permaneceu por muito tempo sob o domínio de um Portugal arcaico, a burguesia chegou quando no seu nascedouro já estava em declínio, ou seja, quando já havia perdido a pujança e o compromisso com seus princípios revolucionários, devemos entender, além do mais, que não existe algo como uma 'classe' social, isso é apenas uma abstração, na verdade o que existe são homens que assumem para si determinados valores e princípios que permite sua identificação a um determinado grupo a que denominamos 'classe', hoje inclusive também uma denominação inadequada, pois tal é a fragmentação desses grupos que somente se pode falar em sub-subclasses. Ora, se os indivíduos mudam a tal ponto que um 'cientista' no poder pede que esqueçam o que ele escreveu e um operário no poder fantasia suas

\begin{tabular}{|l|l|l|l|l|}
\hline Qevista Dialectus & Ano 2 & n. 3 & Julho-Dezembro 2013 & p. 48-56 \\
\hline
\end{tabular}


origens para negar compromissos dos seus tempos de sindicalista, o quanto não deve mudar uma 'classe' na sucessão histórica dos indivíduos que a compõem?

Daí, o que conhecemos ou supomos conhecer no Brasil como burguesia se caracteriza naquele indivíduo que, embora tendo obtido seu capital segundo os moldes da economia burguesa aspira e se comporta conforme a nobreza portuguesa que nos dominou em tempos idos, em consequência torna-se o vilão dos discursos dos sempre presentes demagogos de plantão e na música popular a burguesia fede. Se a burguesia tivesse sido sempre isso que está no imaginário brasileiro, como teria chegado ao poder? Ou ainda, qual a razão dos elogios de um Marx sempre tão crítico? O que nos diz a História?

Com efeito, sabemos que apelar à história é sempre muito delicado, pois a narrativa da história é feita pelos vencedores, mas até nisso a burguesia vencedora não logrou unanimidade em sua apologia, pois venceu o ancien régime como os romanos venceram os gregos, isto é, perdendo a guerra para a cultura dos vencidos. Não obstante, a divisão da história em Idade Antiga, Média e Moderna representar, em termos gerais, a vitória da burguesia, posto que moderno é, desde alguns séculos para cá, tudo o que é atinente à burguesia.

$\mathrm{Na}$ verdade, muitas vezes nos esquecemos do que era a burguesia em suas origens, simples vendedores ambulantes (mascates) que perambulavam pelas vilas e pequenas cidades da Europa, levando produtos dos centros urbanos de maior porte (panelas de metal e bugigangas) e junto com os produtos realizavam a histórica inversão do fluxo de valores do sentido campo $>$ cidade para o sentido cidade $>$ campo, revolucionando todas as relações econômicas e sociais; os burgueses não têm tradição, não têm um passado para cultuar, valorizam o novo com o qual se (com) fundem, mas isso não é tudo, eles também re-significaram o trabalho, toda a origem negativa do trabalho $^{2}$ ganha sentido positivo, através do trabalho o burguês agrega valor ao produto e retira daí o lucro que lhe dá independência econômica, que é a base da liberdade burguesa - somente se é livre quando se é livre economicamente; assim, o trabalho passa de teatro de horrores a fonte de riquezas.

Há ainda a considerar um aspecto muito importante da 'revolução' burguesa, qual seja a realização efetiva do princípio, já conhecido através da representação cristã -

\footnotetext{
${ }^{2} \mathrm{Na}$ sua origem a palavra trabalho vem de trabalhar que remete a tripaliare, do lat. tripalium 'instrumento de tortura', der. do adj. tripális, $e$ 'sustentado por três estacas ou mourões', usado pelos romanos para forçar os escravos a realizarem as tarefas; posteriormente, corresponde aos serviços prestados por homens livres cujo pagamento era feito com o salarìum, porção de sal. Cf. Houaiss - Dicionário da Língua Portuguesa.
} 
da individualidade subjetiva, o indivíduo-sujeito que não vive para o Estado, para a família nem para a Igreja, mas que é formado (no sentido da Bildung hegeliana) para viver para si, é educado numa profissão através da qual irá conquistar a sua liberdade econômica e ser-para-si. Daí, o conceito de pessoa que se transfigura de algo também negativo, uma maneira de se referir a alguém com desdém em algo positivo, dignificante que culmina no conceito moderno de origem kantiana, e do qual hoje ninguém abdica, pessoa é somente o homem que é o ente capaz de encontrar um fim em si mesmo.

Com efeito, não é preciso muita reflexão para descobrirmos nessas determinações originais da burguesia a fonte da maioria dos valores que cultivamos e muitos dos princípios sob os quais vivemos ou dirigimos nossa existência. Não obstante, toda a trans-valoração perversiva de que tudo isso foi e continua a ser objeto desde a ascensão da burguesia ao poder político, pois como se sabe ninguém é ou permanece revolucionário depois da conquista do poder.

Mas, qual o acento burguês que a sociedade civil assume como a sua determinação essencial, conforme a visão hegeliana, a ponto de lhe conferir a denominação burguesa? Nesse ponto, temos de recorrer ao que nosso filósofo denomina de 'Sistema de Carências'. Hegel assim apresenta em sua Filosofia do Direito:

\begin{abstract}
$\S 182$ - A pessoa concreta, que, enquanto particular é para si mesma um fim, como totalidade de carências e como mescla de necessidade natural e de vontade arbitrária, é um dos dois princípios da sociedade civil burguesa. Mas, como a pessoa particular se encontra essencialmente em relação com outra particularidade, de modo que cada um somente pode se afirmar e se satisfazer por meio da outra, sendo assim ao mesmo tempo mediada pela forma da universalidade, que constitui o outro princípio da sociedade civil burguesa. ${ }^{3}$ (FD, p. 339).
\end{abstract}

Com efeito, não é suficiente lembrarmo-nos dos ensinamentos de Aristóteles de que o homem é um animal político, ou seja, que não pode viver isolado, pois aquele que fosse capaz de bastar-se a si mesmo seria um deus ou uma besta, para reconhecer nessa passagem do Hegel a suprassunção dessa antiga formulação no fim do solipsismo do sujeito que aqui está presente, seria necessário retomar a reconstrução hegeliana apresentada na Fenomenologia do Espírito do percurso da consciência-de-si da mera certeza sensível até o saber absoluto ou momento em que o espírito se sabe como

\footnotetext{
${ }^{3}$ Todas as citações da Filosofia do Direito, de G. W. F. Hegel, serão tomadas da edição Suhrkamp Grundlinien der Philosophie des Rechts oder Naturrecht und Staatswissenschaft im Grundrisse, Frankfurt am Main, 1975; em tradução nossa.
} 
espírito, para bem compreender a riqueza conceitual que está presente nessa passagem da Filosofia do Direito.

Ora, embora Hegel não abdique do conceito de pessoa formulado por Kant de que pessoa é somente o homem capaz de encontrar um fim em si mesmo, antes lhe arranque das formulações abstratas para lhe dar efetividade, pelo fato mesmo de que o homem é o conteúdo da relação, o relacionar-se e o relacionar-se a si mesmo, constituindo a si mesmo somente enquanto ato do ser-aí essente, posto que relação implica sempre o múltiplo ou pelo menos algo/alguém que se dá na relação com outro, a necessidade da presença do outro para a pessoa é tão essencial que radica na própria condição ôntico-ontológica do homem.

Por conseguinte, o primeiro princípio da sociedade civil burguesa emerge efetivamente na história com a Modernidade, ou melhor, com aquilo que indicávamos antes como um princípio essencial que caracteriza a formação do burguês - o formar-se para si, mas um para si que depende para a sua existência da presença do outro, se na atividade do trabalho o burguês depende de quem fabrica e de quem compra, igualmente no seu estatuto de dignidade humana depende do reconhecimento do outro da sua condição de pessoa.

No que se refere ao segundo princípio - a universalidade, novamente se teria de recorrer à Fenomenologia do Espírito, de onde retomamos apenas uma passagem de um parágrafo:

\begin{abstract}
Com efeito, a linguagem é o ser-aí do puro $\mathrm{Si}$, como si; pela linguagem entra na existência a singularidade para si essente da consciência-de-si como tal, de forma que ela é para os outros. O Eu, como este puro Eu, não está aí de outra maneira: em qualquer outra exteriorização está imerso em uma efetividade e em uma figura da qual pode retirar-se; é refletido sobre si mesmo a partir de sua ação, como também de sua expressão fisiognômica, deixando jazer inanimado um tal ser-aí imperfeito no qual está sempre tanto demasiado, como demasiado pouco. Mas a linguagem contém o Eu em sua pureza; só expressa o Eu, o Eu mesmo. Esse ser-aí do Eu é, como ser-aí, uma objetividade que contém a verdadeira natureza dele. O Eu é este Eu, mas é igualmente o Eu universal. Seu aparecer também é imediatamente a extrusão e o desvanecer deste Eu, e por isso seu permanecer em sua universalidade. $\mathrm{O}$ $E u$ que se expressa é escutado: é um contágio, no qual passou imediatamente à unidade com aqueles para os quais 'está-aí, e é consciência-de-si universal. (FE, § 508, p. 350-351).
\end{abstract}

Evidentemente aqui não se diz tudo, mas se diz muito, a universalidade não pode ser pensada de modo abstrato, tem de ser apreendida a partir do que constitui a própria condição humana, nesse sentido a linguagem, da qual se tem dificuldade de decidir se o homem a criou ou se somente se constitui como humano na posse da linguagem, que 
traz como uma necessidade imanente ou exigência o universal, pois uma linguagem que fosse singular seria um código indecifrável, mesmo as gírias da juventude ou as brincadeiras infantis como a 'língua do p' têm que ser universalizadas no interior do grupo que através dela se comunica.

A linguagem, da qual Hegel já disse ser o mais verdadeiro, permite à pessoa sair de si permanecendo em si, extrusar-se, dar efetividade a uma manifestação positiva através da qual o outro pode lhe reconhecer como outro de si mesmo, somente sendo para outro se pode ser para si. Pode-se objetar levantando a questão: E quando através da linguagem se usa de dissimulação, a linguagem permanece sendo o mais verdadeiro? Sim, pois aí seria a verdade da dissimulação, vale sempre ter isso presente em tempos de simulacro como o nosso.

Com efeito, a escuta é elemento essencial na dialética do reconhecimento, através da escuta não só o outro se torna presente para o Eu, para a pessoa que na linguagem se manifesta, mas também o Eu que escuta se revela como abertura para o outro na partilha do mundo enquanto totalidade dinâmica de significados sempre fluentes, evanescentes e desvanescentes. Mundo que em todo caso é o mundo da pessoa, da pessoa que é o mundo, que na partilha se compartilha a unidade.

Não é sem razão, portanto, que Hegel afirma na Filosofia do Direito, no parágrafo que se segue ao supracitado:

\begin{abstract}
§183 - O fim egoísta, assim condicionado na sua realização pela universalidade, funda um sistema de dependência recíproca tal que a subsistência, o bem estar do indivíduo e sua existência jurídica estão estreitamente ligados à subsistência, ao bem estar e ao direito de todos, sobre isso estão fundados e somente nessa conexão tem realidade efetiva e são preservados. Pode-se, em primeiro lugar, considerar esse sistema como o Estado exterior, - como o Estado da necessidade e do entendimento. (FD, p. 340)
\end{abstract}

Nesse sentido a dependência recíproca é multilateral e polissêmica, perpassa todas as dimensões da existência humana, e na medida em que a sociedade civil na sua determinação burguesa sobrepõe o econômico, o jogo de forças econômicas, como fator que não apenas em última instância, mas que já de início é o pressuposto da própria formação humana, em que todo o sistema de educação está voltado para atender as necessidades do mercado e mesmo a cidadania é medida em função da qualidade de vida proporcionada pelos recursos econômicos, difícil não concordar com Hegel de que seja essa característica mais acentuada de nossa sociedade civil moderna e contemporânea.

Ainda que Hegel assinale, didaticamente, que:

\begin{tabular}{|l|l|l|l|l|}
\hline Qevista Dialectus & Ano 2 & n. 3 & Julho-Dezembro 2013 & p. 48-56 \\
\hline
\end{tabular}


$\S 190$ - O animal tem um círculo limitado de meios e de modos de satisfazer as suas carências, igualmente limitadas; o homem, mesmo nessa dependência, mostra a sua capacidade de ultrapassar e sua universalidade, de início, pela multiplicação das carências e dos meios, em seguida em divisando e distinguindo a necessidade concreta nas partes e lados isolados, que formam diferentes carências particularizadas e, por conseguinte, mais abstratas.

Obs.: No direito, o objeto é a pessoa, no ponto de vista moral é o sujeito, na família é o membro da família, na sociedade civil burguesa em geral é o cidadão como bourgeois. Aqui, no ponto de vista das carências (cf. § 123, Obs.), é esse concretum da representação a que chamamos homem. Por conseqüência, é unicamente a partir de agora, e também, na verdade, apenas aqui, que se fala do homem neste sentido. (FD, p. 347-348)

$\mathrm{Na}$ verdade, é o homo oeconomicus que prevalece e subsume nele todas as dimensões da existência, como Hegel bem acentua é o cidadão como bourgeois e não como citoyen que caracteriza a sociedade civil burguesa. $\mathrm{O}$ cidadão que se afirma como aquele que consome, que exige direitos porque paga impostos, enfim, que coloca o seu reconhecimento não na condição humana total, mas na redução que opera o sistema econômico que transfere ao ter aquilo que seria próprio do ser.

Por conseguinte, não é de se estranhar que:

$\S 185$ - De um lado, a particularidade para si que, por sua atividade multiforme, é busca da satisfação de suas necessidades, livre arbítrio contingente, preferência subjetiva, destrói a si mesma nessa fruição e destrói também seu conceito substancial. De outro lado, como a satisfação da necessidade é uma exigência que se renova sem cessar, como ela está em perpétuo estado de dependência à respeito da realidade contingente exterior e do arbítrio, como ela está limitada pela potência do universal, esta satisfação - quer se trate da carência necessária ou uma necessidade contingente permanece sempre contingente. A sociedade civil burguesa, nessas oposições e no seu entrelaçamento, oferece-nos tanto o espetáculo da extravagância, como da miséria e da corrupção tanto física quanto ética comuns a ambos. (FD, p. 341)

Segundo Hegel, a Filosofia deve ocupar-se com o que é, o filósofo deve ser capaz de traduzir seu tempo em conceito, daí que a leitura dessa passagem nos faz viver o tempo histórico de Hegel, já que a história tem seu tempo pensado em termos de séculos e não em meses ou dias, pois ao olhar para a nossa realidade atual e nos darmos conta de suas mazelas, de tanta miséria e corrupção em todos os âmbitos da sociedade civil, parece-nos inevitável julgar que esse texto nos alcança, que esse momento da história que nele se apresenta ainda não passou, que a realidade aqui descrita é a nossa.

Para aqueles que entendem que nosso tempo é outro, que a tecnologia nos trouxe um outro tempo que em nada corresponde ao momento da escritura do texto da Filosofia do Direito de Hegel, e por conseguinte, o conteúdo do texto está anacrônico, convidamos-lhes a ler conosco um pouco mais essa caracterização da sociedade civil burguesa:

\begin{tabular}{|c|c|c|c|c|}
\hline Qenista Qialectus & Ano 2 & n. 3 & Julho-Dezembro 2013 & p. $48-56$ \\
\hline
\end{tabular}




\begin{abstract}
$\S 191$ - Os meios que permitem satisfazer as carências particulares se partilham e se multiplicam, assim como, as modalidades de sua satisfação que se tornam fins relativos e carências abstratas; essa multiplicação, que prossegue até ao infinito, na medida em que intervém um fator de distinção na determinação dessas carências e um esforço de apreciação destinado a adaptar os meios aos fins, constitui o refinamento.

Adendo. $\mathrm{O}$ que os ingleses designam por comfortable é qualquer coisa de inesgotável que se diversifica ao infinito, cada conforto alcançado acaba por fazer prova de seu desconforto, de maneira tal que as invenções não têm fim. Por isso uma carência é produzida não tanto pelos que a sentem de modo imediato, mas, muito mais pelas pessoas que procuram realizar lucro fazendo-a nascer. (FD, p. 348-349)
\end{abstract}

Com efeito, a tecnologia na medida mesmo em que acelera o processo de produção de bens a uma velocidade tão grande que no momento em que se adquire um produto, de imediato, ele se torna ultrapassado, - por exemplo: compramos um comutador pessoal portátil de última geração e modelo e ao chegar em casa o conectamos a internet, acessamos virtualmente a indústria que o produziu e descobrimos ali novos modelos sendo lançados e a serem comercializados que deixam na poeira da história o que acabamos de adquirir, - apenas acentua enfaticamente um confortable inesgotável que se estende indefinidamente.

Além do mais, A burguesia não pode existir senão a condição de revolucionar incessantemente os instrumentos de produção e, por conseguinte, as relações de produção, e com isso todas as relações sociais. Significa dizer que a tecnologia e seus produtos são os meios através do quais a burguesia promove a mudança para que nada mude ou, como diriam os franceses: plus ça change, plus ça la même chose.

Mas, a que espetáculo assistimos nos dias de hoje? Eis a cena: a muralha da China - transformada em fonte de recursos para a indústria capitalista do turismo -, assiste placidamente os chineses produzirem a preços baixos para prover a sociedade civil burguesa e seu sistema econômico da artilharia pesada que derruba todas as muralhas da China.

Por fim, vale ressaltar que:

$\S 246$ - Por esta dialética, a sociedade civil burguesa é empurrada para fora e para além de si mesma, sendo primeiramente em tal sociedade determinada, para ir em seguida buscar fora dela, em outros povos atrasados em relação a ela, os meios necessários à sua subsistência e consumidores, no que concerne aos meios que ela possui em abundância ou, de uma maneira geral, indústria e consumidores, portanto, os meios de subsistência necessários. (FD, p. 391)

Universalização, mundialização, globalização não importa a palavra que usemos para descrever esse processo, importa manter a esperança de que o Espírito é tanto maior quanto maior a contradição da qual retorna a si mesmo, e assim, laborarmos no 
sentido de que os aspectos da sociedade civil burguesa que degradam nossa condição humana venham a ser suprassumidos, e nessa suprassunção esses aspectos sejam negados como realidade efetiva, conservados como memória que não desejamos repetir e que nos elevemos a uma situação tal que a dignidade humana deixe de ser uma aspiração, uma meta distante e esteja presente em todos os atos que nos constituem.

\section{Referências}

HEGEL, G. W. F. Grundlinien der Philosophie des Rechts oder Naturrecht und Staatswissenschaft im Grundrisse. Frankfurt am Main, Suhrkamp, 1975.

Fenomenologia do Espírito. $7^{\mathrm{a}}$ ed. Petrópolis: Vozes, 2002.

MARX, K. \& ENGELS, F. Manifiesto del Partido Comunista. In: Obras Escogidas. Moscou, Editorial Progreso, s/d. 